\title{
Sedation for flexible bronchoscopy: current and emerging evidence
}

\author{
Ricardo J. José*,\#, Shahzad Shaefi ${ }^{\top}$ and Neal Navani*,+
}

\begin{abstract}
Flexible bronchoscopy is commonly performed by respiratory physicians and is the gold standard for directly visualising the airways, allowing for numerous diagnostic and therapeutic interventions. With the widespread use of flexible bronchoscopy and the evolution of interventional bronchoscopy with more complex and longer procedures, physicians are placing increasing importance on the use of sedation as a necessary adjunct to topical anaesthesia. There is no standardised practice for the use of sedation in bronchoscopy with a good deal of variation among physicians regarding the use of pre-procedure medication and pharmacological sedatives. In addition, there is ongoing debate and controversy about proceduralist-administered versus anaesthetist-administered sedation whilst at the same time there is a growing body of evidence that nonanaesthetist administered sedation is safe and cost-effective. In this review we summarise the evidence for the use of sedation as an adjunct to topical anaesthesia in bronchoscopy and provide the clinician with up-todate concise guidance for the use of pharmacological sedatives in bronchoscopy and future directions for sedation in the bronchoscopy suite.
\end{abstract}

KEYWORDS: Anaesthesia, bronchoscopy, midazolam, proceduralist administered, propofol, sedation

$\mathbf{F}$ lexible bronchoscopy is commonly performed by respiratory physicians and is the gold standard for directly visualising the airways, allowing for numerous diagnostic and therapeutic interventions. With the widespread use of flexible bronchoscopy and the evolution of interventional bronchoscopy with more complex and longer procedures, physicians are placing increasing importance on the use of sedation as a necessary adjunct to topical anaesthesia. Some physicians perform the procedure without sedation. Indeed, one study suggested that although midazolam may facilitate the performance of the procedure for the operator, it does not improve patient comfort [1]. Another study showed that with the proper patient selection, awake bronchoscopy is well tolerated [2]. However, the majority of physicians now use pharmacological sedatives [3] and anxiolytics, improving procedural tolerance and patient satisfaction, as shown by several case-control studies and randomised controlled trials [4-8]. There is no standardised practice for the use of sedation

\footnotetext{
*Dept of Thoracic Medicine, University College Hospital, London, ${ }^{*}$ Centre for Inflammation and Tissue Repair, University College London, London, ${ }^{+}$Lungs for the Living Research Centre, University College London, London, UK. "Dept of Anaesthesia, Critical Care and Pain Medicine, Beth Israel Deaconess Medical Center, Boston, MA, USA.
}

CORRESPONDENCE: R.J. José, Dept of Thoracic Medicine, University College Hospital London, 250 Euston Road, London, NW1 2BU, UK. E-mail: r.jose@ucl.ac.uk

Received: Oct 23 2012; Accepted after revision: Oct 112012

PROVENANCE: Submitted article, peer reviewed. in bronchoscopy with a good deal of variation among physicians regarding the use of pre-procedure medication and pharmacological sedatives [3, 9]. Only recently has more specific guidance been published on this by a society of respiratory specialists in the American College of Chest Physicians consensus statement [10]. In addition, there is ongoing debate and controversy about proceduralist-administered versus anaesthetist-administered sedation whilst at the same time there is a growing body of evidence that nonanaesthetist administered sedation is safe [11, 12] and costeffective [13].

Topical anaesthesia is imperative for both patient and operator satisfaction but this topic is beyond the remit of this review. In this review we summarise the evidence for the use of sedation as an adjunct to topical anaesthesia in bronchoscopy (inpatient and outpatient setting) and provide the clinician with up-todate concise guidance for the use of pharmacological sedatives in bronchoscopy and future directions for sedation in the bronchoscopy suite.

\section{MODERATE SEDATION}

In most settings, sedation is not administered by an anaesthetist but by the bronchoscopist (proceduralist-administered sedation) who is ultimately responsible for the patient under their care. It is therefore important that the bronchoscopist can administer pharmacological sedatives safely to render depression of the level of consciousness to a level that is sufficient to carry out the procedure; achieving procedure tolerance without 
compromising the patient's ability to maintain a patent airway, and ventilatory and cardiovascular function. A moderate level of sedation should be achieved and this is sometimes referred to as conscious sedation whereby the techniques used are unlikely to render the patient unconscious and the patient is able to respond to verbal commands. If the patient is only responding to painful stimulus in the form of reflex withdrawal, then a level of deep sedation has been obtained and the ability to independently maintain ventilatory function or a patent airway may be impaired [14].

\section{SAFE DELIVERY OF MODERATE SEDATION}

To achieve the required level of sedation, the chosen pharmacological sedative should be administered by titration of small incremental doses to the desired clinical and physiological effect, irrespective of being given in boluses or as a continuous infusion. This is particularly important in patients where the arm-brain circulation time (time taken for the drug to travel from the injection site to the brain and have its central nervous system effect) is prolonged (e.g. heart failure). In the elderly, dose adjustments are particularly important due to the reduced hepatic metabolism and renal function, reduced tissue and blood esterases and increased sensitivity to a given concentration of drug [15]. Dose adjustments may also be required in substance misusers, recipients of stem-cell transplants, patients with cystic fibrosis (after lung transplantation), American Society of Anesthesiology (ASA) physical status category 3 and 4 patients (especially those with severe renal or hepatic dysfunction), and where drug interactions enhancing or inhibiting their effects are used [16-18]. The depth of sedation should always be monitored throughout the procedure and documented using the Ramsay scale [19] (table 1). For moderate sedation a depth of sedation should not be greater than that of level 3. Bispectral (BIS) index monitoring is an electroencephalographic-based method of assessing a patient's level of consciousness and has been used in two trials of moderate sedation for bronchoscopy [20, 21]. Both studies concluded that BIS can be used safely by the nonanaesthetist to titrate sedation with propofol. Further studies are required to determine if the use of BIS monitoring is more cost-effective than the use of clinical judgement alone. Due to the risk of bradycardia, hypotension and respiratory depression associated with the use of pharmacological sedatives patients should be appropriately monitored with the continuous measurement of pulse rate and oxygen saturations, and frequent blood pressure.

Before commencing the procedure it may be useful that the bronchoscopist and the unit staff go through a checklist

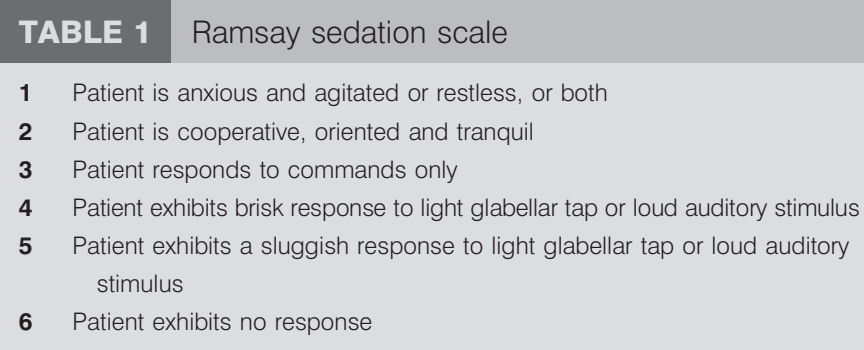

(table 2), adapted from the WHO surgical checklist [22], to ensure that they are adequately prepared to safely administer the sedation, perform the bronchoscopy and recover the patient. Each unit should have an adequately equipped postprocedure recovery with monitoring of respiratory and cardiovascular physiology and support to deal with potential complications. Monitoring should continue after completion of the procedure until complete recovery of sedation has been observed and recorded. Parameters that should be assessed as criteria for safe discharge should include stable vital signs, respiratory function with airway patency, adequate cardiovascular status and an awake, alert and comfortable patient. Time to reach these criteria can be highly variable based on patient factors and medication choices.

\section{PRE-MEDICATION DRUGS IN BRONCHOSCOPY Anti-cholinergic drugs}

Anti-cholinergic drugs, such as atropine and glycopyrrolate, have been used due to their sympathetic effects which can prevent vasovagal reactions (bradycardia), and reduce coughing and airway secretions which may improve procedure tolerance and visualisation of the airways. In the past they were used as standard practice by many bronchoscopists but in clinical trials these drugs have failed to demonstrate benefits in bronchoscopy. COWL et al. [23] and MALIK et al. [24] compared intramuscular atropine and glycopyrrolate to placebo. Cowl et al. [23] found no significant benefit in the use of anti-cholinergics in reducing secretions, cough and complication rates or in increasing patient comfort. Despite demonstrating a reduction in airway secretions MALIK et al. [24] found no benefits on patient comfort, oxygen desaturation or the time it took to complete the procedure and there were greater haemodynamic fluctuations and rise in blood pressure and pulse rate with the use of atropine.

\section{Clonidine}

Clonidine, a centrally acting $\alpha_{2}$-adrenergic agonist, has been used due to the sympatholytic effects on the cardiovascular system that may reduce the incidence of arrhythmias and

\section{TABLE 2 Pre-sedation flexible bronchoscopy checklist}

Patient identifier (name, date of birth)

Consent form signed

Responsible adult available to escort the patient post-procedure

Adequate fasting period

Allergies

Hepatic and renal function (if the clinical history suggests these could be abnormal)

Observations (vital signs)

Continuous pulse oximetry available

Intravenous access functioning

Medications checked

Resuscitation trolley available with emergency drugs

Reversal drugs available (flumazenil and naloxone)

Oxygen available (including variety of oxygen delivery devices)

All staff ready for the procedure to commence

Data from [22] 
myocardial infarction during bronchoscopy, which is often associated with tachycardia and hypertension [25]. In a small randomised controlled trial, MATOT and KRAMER [26] showed that oral clonidine attenuated the haemodynamic response to flexible bronchoscopy but with higher doses $\left(4-4.5 \mu \mathrm{g} \cdot \mathrm{kg}^{-1}\right)$ it resulted in hypotension. In a trial of intravenous clonidine, DE PADUA et al. [27] demonstrated the beneficial effect of clonidine on blood pressure and heart rate with a reduction in frequency in arrhythmias but didn't demonstrate an improvement in patient comfort. Clonidine is probably not used more frequently due the prolonged sedative effects of oral administration, the rebound hypertension seen occasionally on withdrawal of the drug and the lack of larger randomised controlled trials [28].

\section{Labetalol}

Labetalol is an $\alpha_{1}$ - and $\beta_{1} / \beta_{2}$-antagonist used for its ability to reduce peripheral vascular resistance and arterial blood pressure without causing a reflex tachycardia. Fox et al. [29] performed a randomised controlled trial of intravenous labetalol versus placebo in addition to midazolam-alfentanil sedation and found no beneficial effect of adding labetalol as patients appropriately sedated with midazolam-alfentanil had adequate attenuation of their sympathetic stress responses.

\section{Dextromethorphan}

Dextromethorphan is a non-competitive N-methyl-D-aspartate (NMDA) receptor antagonist with anti-tussive properties that has been used in bronchoscopy with midazolam sedation by ScHWARZ et al. [30]. Dextromethorphan (dose of $90 \mathrm{mg}$ ) led to a reduction in cough with less topical lignocaine and midazolam being required, whilst achieving better analgesia and patient comfort.

\section{Fenoterol}

Fenoterol is an inhaled short-acting $\beta_{2}$-agonist. It was used preprocedure in addition to intramuscular atropine and hydroxyzine by VESCO et al. [31] in a small, randomised controlled trial. Fenoterol, in addition to atropine was found to have significant anti-tussive effects leading to less topical lignocaine being used.

\section{Codeine phosphate}

Codeine phosphate is an opiate with analgesic and anti-tussive properties and has been assessed by TSUNEZUKA et al. [32] in bronchoscopy as an adjunct to sedation with midazolam. The authors found that the addition of codeine phosphate $0.4 \mathrm{mg} \cdot \mathrm{kg}^{-1}$ given orally $60 \mathrm{~min}$ before the procedure led to a reduction in the dosage of topical anaesthetic and the degree of oxygen desaturation compared to placebo. Codeine is converted by cytochrome P450 2D6 (CYP2D6) to morphine but genetic polymorphisms exist that alter the conversion of the drug, leading to decreased effect in slow metabolisers and an increased effect and complications in ultra-rapid metabolisers [33]. The use of this drug has been replaced in bronchoscopy by newer short-acting opiates.

\section{Benzodiazepines}

Lorazepam and temazepam have been found to improve patient comfort and willingness to undergo a future procedure and this was thought to be related to its amnesic effect as patients were less likely to recall the procedure [34, 35]. These drugs have now been replaced by midazolam with more favourable properties and used in intra-procedural sedation.

With the present methods of sedation, pre-medication does not appear to be necessary to improve procedure tolerance and patient satisfaction. The administration of pre-medication may, in this case, lead to the potential of over-sedation and adverse effects. However, more trials of the use of clonidine and labetalol or other sympatholytic agents are needed to evaluate the effect on the reduction of arrhythmias and myocardial infarction.

\section{PHARMACOLOGICAL SEDATIVES USED FOR SEDATION DURING BRONCHOSCOPY}

An ideal sedative for use in outpatient bronchoscopy should be easy to use, have a rapid onset, short duration of action, and rapid recovery with rapid return of cognition. It should have a predictable pharmacokinetic and pharmacodynamic profile that is not altered by interactions with other drugs and should be reversible with a predictable and specific antagonist. Ultimately, its properties and use should result in improved safety of the procedure, as well enhance patient comfort and tolerance. A summary of the properties of pharmacological sedatives commonly used in bronchoscopy are listed in table 3 .

\section{Benzodiazepines}

Benzodiazepines have a long history of safety and efficacy in bronchoscopy and are widely used for sedation. These drugs enhance the effect of the gamma-aminobutryic acid (GABA) and have sedative, hypnotic, anxiolytic, anti-convulsant and muscle relaxing properties [18]. In higher doses they may have amnesic-dissociative properties, which have been reported to be a reason why patients are less reluctant to have another bronchoscopy in the future if needed [34]. Another advantage is the ability to safely and effectively reverse their action with the antagonist, flumazenil, which must be available in every unit if these drugs are going to be used for sedation [37]. Benzodiazepines are metabolised in the liver via the cytochrome P450 (CYP) 3A4 and 3A5 system and excreted mainly in the urine. Due to natural variability in this system among various populations, the elimination half-life of these drugs may be prolonged in $5-8 \%$ of the population [38]. Midazolam has a large volume of distribution similar to diazepam but a short elimination half-life $(2 \mathrm{~h})$ and faster onset of action [18].

Benzodiazepines have relatively small cardiovascular depressant effects and only result in slight decreases in arterial blood pressure and increases in heart rate with some decrease in vagal tone resulting in heart rate variability seen with midazolam [18]. The ventilatory drive is depressed and although apnoea is not usually seen with low doses used for moderate sedation this may occur with higher doses, in those with comorbidities and when used in combination with other respiratory depressants.

Flumazenil, an imidazobenzodiazepine derivative, is a competitive antagonist of benzodiazepines at the GABA receptor and is used for reversal of benzodiazepine effects. It has a shorter half-life than the benzodiazepines used in bronchoscopy so its effect may cease before that of the benzodiazepine and lead to re-depression of the respiratory drive unless supplemental doses are given. It is essential that the patient is 


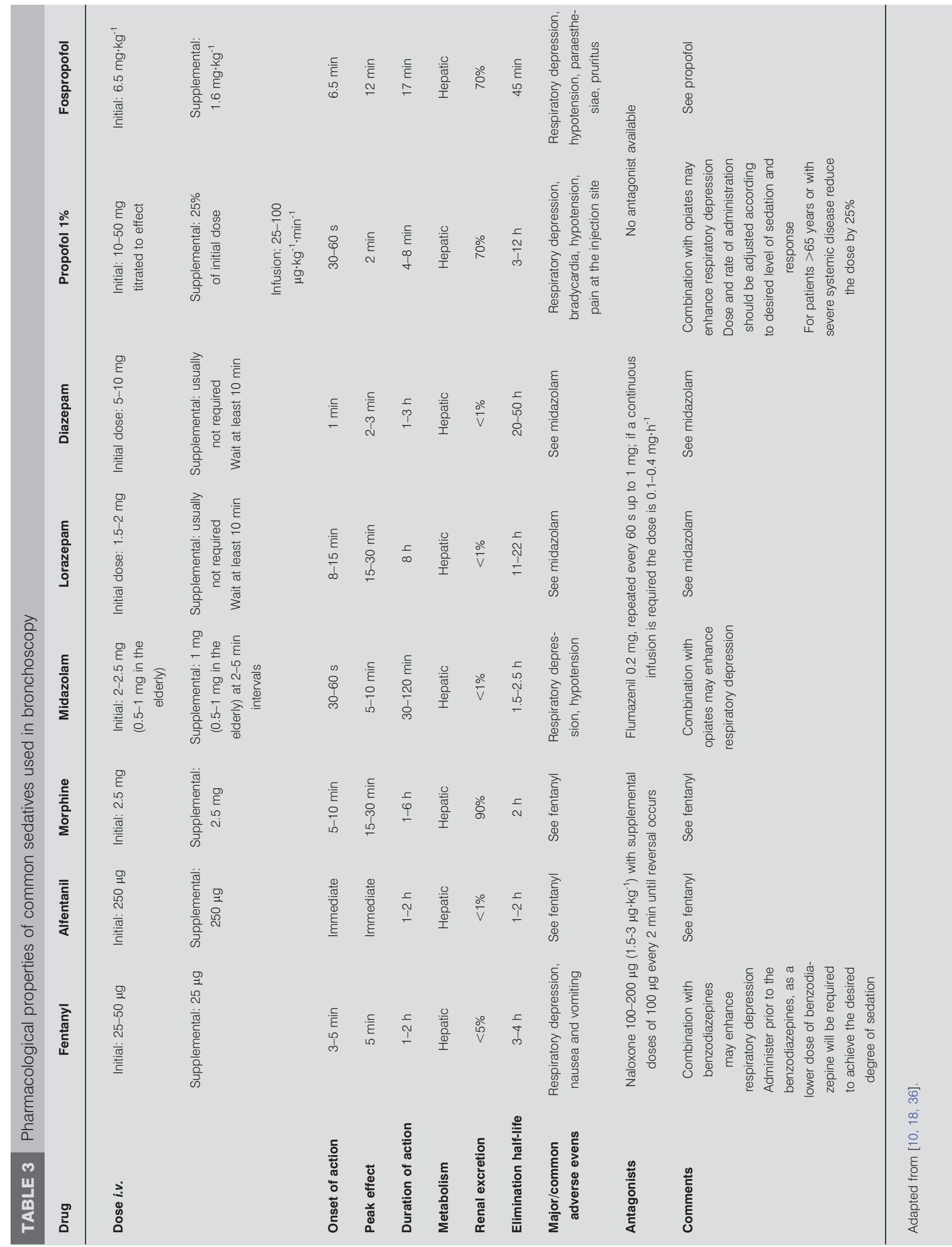


appropriately monitored until the effect of the benzodiazepine has completely ceased without supplemental doses of the antagonist. For reversal of benzodiazepine sedation, the dose of flumazenil is $0.2 \mathrm{mg}$, repeated every $60 \mathrm{~s}$ up to $1 \mathrm{mg}$; if a continuous infusion is required the dose is $0.1-0.4 \mathrm{mg} \cdot \mathrm{h}^{-1}$ [39].

Lorazepam [34] and diazepam [4] have been used in bronchoscopy but midazolam is the most frequently used benzodiazepine due to its properties having advantageous effects over others, especially the rapid onset of action, rapid time to peak effect and short duration of action [18]. The doses used for sedation of midazolam, lorazepam and diazepam are 0.01$0.1 \mathrm{mg} \cdot \mathrm{kg}^{-1}, 0.03-0.05 \mathrm{mg} \cdot \mathrm{kg}^{-1}$ and $0.04-0.2 \mathrm{mg} \cdot \mathrm{kg}^{-1}$, respectively [18]. In a recent randomised controlled trial, RoLo et al. [7] showed that patients sedated with midazolam had less cough and dyspnoea and had increased patient-reported comfort and willingness to have a repeat procedure compared with placebo. This has been previously shown by others, such as CASES VIEDMA et al. [40] who also showed that the use of midazolam, reduced operator difficulties in performing the procedure and procedure time. Midazolam has been used safely and effectively in combination with opiates [8].

\section{Opioids}

Opioids are now frequently used in bronchoscopy in combination with benzodiazepines for their analgesic, anti-tussive and sedative properties. These properties complement those of the benzodiazepines, offering advantages in improving conditions for the bronchoscopist, improving patient tolerance of the procedure and attenuating sympathetic responses associated with intubation. At the same time it leads to a reduction in the amount of other pharmacological sedatives (e.g. benzodiazepines and propofol).

Opioids bind to mu $(\mu)$, kappa $(\kappa)$, delta $(\delta)$ and sigma $(\sigma)$ receptors that are found in the brain, spinal cord, peripheral sensory neurons and gastrointestinal tract [18]. The opioids used in bronchoscopy are agonists mainly of the $\mu$ receptor, responsible for supraspinal analgesia, respiratory depression and muscle rigidity [18]. They are mainly metabolised by the liver and excreted in by the kidneys. Due to renal elimination, opioids (especially morphine) can accumulate (metabolites) in patients with renal failure leading to prolonged sedation and ventilatory depression. In high doses opioids lead to bradycardia and associated hypotension but do not depress cardiac contractility. The effects on the respiratory system are more noteworthy, particularly reduction of the respiratory rate resulting in ventilatory depression. Due to the effects of opioids on the respiratory centres in the brainstem the apnoeic threshold is increased and the hypoxic drive is reduced.

Naloxone is the competitive opioid antagonist at the $\mu, \kappa$ and $\delta$ receptors. The intravenous dose for reversal of opioid respiratory depression and over sedation is usually 100 $200 \mu \mathrm{g}\left(1.5-3 \mu \mathrm{g} \cdot \mathrm{kg}^{-1}\right)$ with supplemental doses of $100 \mu \mathrm{g}$ every 2 min until reversal occurs to the desired level of respiration and consciousness [41]. With a short mean half-life of $64 \mathrm{~min}$, over sedation may recur and an infusion or repeated dosing every 1-2 h [42] may be required.

Fentanyl is 100 times as potent as morphine and has a more rapid onset of action and elimination half-life making it more suitable for use in bronchoscopy [43]. The recommended dose of fentanyl in moderate sedation is $50-200 \mu \mathrm{g}$ followed by supplemental doses of $50 \mu \mathrm{g}$ but, at the upper limit of this range, ventilatory depression is more likely, especially when co-administered with other sedatives; therefore, an initial dose of $25-50 \mu \mathrm{g}$ is recommended with supplemental doses of $25 \mu \mathrm{g}$ as required until the desired effect is achieved or a total dose of $200 \mu \mathrm{g}$ has been reached. Continuous infusion at a rate of $0.05-$ $0.08 \mu \mathrm{g} \cdot \mathrm{kg}^{-1} \cdot \mathrm{min}^{-1}$ may also be used [42]. It is important to realise that in most circumstances doses of $200 \mu \mathrm{g}$ are not required and that the dose needs to be reduced when used in combinations with other sedatives. PAPAGIANNIS and SMITH [44] reported their observation of consecutive patients receiving either fentanyl (dose range $50-100 \mu \mathrm{g}$ ) or midazolam (dose range $5-15 \mathrm{mg}$ ) in addition to pre-medication with oral lorazepam and atropine for flexible bronchoscopy. They did not report any significant differences between the two except for the reduction in cough in those receiving fentanyl.

Alfentanil is less potent than fentanyl, but it has an almost immediate onset of action and shorter elimination half-life [45]. An initial dose of $250-500 \mu \mathrm{g}$ is given followed by $250 \mu \mathrm{g}$ supplemental doses as required [45]. Houghton et al. [46] conducted a randomised controlled trial of alfentanil versus midazolam for flexible bronchoscopy. They did not demonstrate large differences in outcomes between the two groups. Those receiving alfentanil had less cough but patients reported more discomfort. In the randomised controlled trial by HWANG et al. [47] the combination of propofol and alfentanil preserved haemodynamic stability throughout the procedure but mean oxygen saturation dropped below $90 \%(87.3 \pm 7.3 \%)$ after the initial bolus, immediately before the procedure, but this was transient with oxygen saturation levels returning to baseline after starting the procedure with no patients requiring assisted ventilation. When used in combination with midazolam, Fox et al. [29] found that these patients had adequate sedation and attenuation of sympathetic responses. DREHER et al. [48] compared consecutive patients with stable pre-existing respiratory failure undergoing flexible bronchoscopy receiving midazolam alone or midazolam-alfentanil combination. They did not find any differences in oxygen desaturation or hypoventilation but those in the combination group reported less discomfort. GREIG et al. [49] compared midazolam alone, alfentanil alone and midazolam-alfentanil combination for flexible bronchoscopy. Alfentanil provided adequate sedation and with its anti-tussive properties significantly attenuated coughing. The combination of midazolam-alfentanil though did not provide better sedation or improve patient tolerance and was associated with a greater risk of oxygen desaturation. The only advantage of alfentanil over fentanyl when used for moderate sedation is its quicker onset of action and shorter sedation time [50] although in bronchoscopy there have been no trials directly comparing these two short-acting opioids.

\section{Propofol}

Propofol (2,6-diisopropylphenol) is a short-acting anaesthetic agent with a rapid onset of action that has been used in bronchoscopy for moderate sedation. It is rapidly metabolised, mainly by conjugation in the liver, with a short initial distribution half-life (2-8 $\mathrm{min}$ ) and initial two-phase elimination half-life of 30-60 min allowing rapid recovery $[18,51]$. It works by binding to the $\beta$-subunit of the GABA-A receptor 
increasing the chloride conductance and results in hyperpolarisation of the post-synaptic membrane [18]. The major effects on organ systems are on the cardiovascular, respiratory and central nervous system and it is used for its hypnotic, antiemetic and anti-pruritic effects but it does not have any analgesic properties. It causes a decrease in systemic vascular resistance and cardiac contractility resulting in a drop in the arterial blood pressure. Propofol can attenuate upper airway reflexes and can cause profound respiratory depression leading to apnoea at induction doses and in doses used for conscious sedation it can inhibit the hypoxic ventilatory drive. Propofol may cause pain on injection but this may be reduced by using the vein in the antecubital fossa, pre-treatment with opioids or pre-treatment with lignocaine together with venous occlusion if a hand vein is used [52].

Propofol is manufactured in a lipid-based oil emulsion that contains soybean oil, egg lecithin, and glycerol [51]. It is not necessarily contra-indicated in patients with egg allergy because most egg allergies are due to ovalbumin in the egg white and egg lecithin is extracted from highly purified egg yolk [53]. There is an increased risk of bacterial infection of propofol vials as it contains no anti-bacterial preservatives [51].

Propofol can be administered intravenously by bolus doses or as a continuous variable rate infusion but the latter is preferable to minimise undesirable cardiorespiratory effects. For induction of sedation a dose of $0.5-1 \mathrm{mg} \cdot \mathrm{kg}^{-1}$ over $1-5 \mathrm{~min}$ is usually required followed by maintenance concentrations of $1.5-4.5 \mathrm{mg} \cdot \mathrm{kg}^{-1} \cdot \mathrm{h}^{-1}$ (concentrations needed for the maintenance of anaesthesia in normal individuals range 4$12 \mathrm{mg} \cdot \mathrm{kg}^{-1} \cdot \mathrm{h}^{-1}$ ) [51]. When administered as a sole agent, a single intravenous bolus dose of $0.5-1.0 \mathrm{mg} \cdot \mathrm{kg}^{-1}$ given at a rate of $40 \mathrm{mg}$ over $10 \mathrm{~s}$ until the desired level of sedation is achieved (1-2.5 $\mathrm{mg} \cdot \mathrm{kg}^{-1}$ for induction of anaesthesia) with top up doses of $25-50 \mathrm{mg}$ every few minutes as required [51].

Randomised controlled studies of the use of propofol in bronchoscopy are summarised in table 4 . These studies have demonstrated that sedation with propofol compared to no sedation leads to less cough, pain, sensation of asphyxiation, total amnesia and improved tolerance of the procedure with no differences in oxygen saturations between the groups [5]. Compared to sedation with midazolam, propofol has similar efficacy and safety [21] but faster onset of action and a more rapid patient recovery for propofol leading to early discharge [20, 21, 54-56] and improved patient tolerance [20, 21, 54-56]. Propofol can be administered with other pharmacological agents including opiates. This results in a lower required dose of propofol, improves sedation, reduces cough and provides analgesia [47, 58, 60, 61]. YoON et al. [57] compared propofol alone and the co-administration of propofol-alfentanil but did not find differences in patient or bronchoscopist satisfaction or in the degree of coughing, but those in the alfentanil group had significantly lower oxygen saturation levels. However, the lower levels of oxygen saturation reported in the alfentanil group are most likely not clinically significant. CARMI et al. [59] compared propofol to midazolam-alfentanil sedation whilst monitoring carbon dioxide tension and they found both to be equally safe but those in the midazolam-alfentanil group rather than the propofol group had higher carbon dioxide tension values and required more oxygen supplementation or airway support.
Due to the narrow therapeutic window between moderate sedation and anaesthesia with the use of propofol, and without the availability of an antagonist, it is generally recommended that it be used only by those formally trained in its use (e.g. anaesthetists) in an appropriate setting and with monitoring as used for deep sedation. Worldwide its use by non-anaesthetists remains controversial although in the literature it is extensively reported to have been used safely and effectively by nonanaesthetists either alone or in combination with other pharmacological sedatives [12, 56, 58, 62-67]. In the future, formal training and competency assessments in sedation practice for bronchoscopy may include the use of propofol given the evidence of benefit to patients.

\section{Ketamine}

Ketamine has been used in flexible bronchoscopy and endoscopy, especially for the paediatric population [68, 69]. Ketamine is a structural analogue of phencyclidine, a noncompetitive NMDA receptor antagonist and partial agonist at opioid $\mu$-receptors that has many central nervous system effects and dissociates the thalamus from the limbic cortex resulting in dissociative anaesthesia with the patient appearing conscious but unable to respond to sensory input [18]. It is biotransformed in the liver (mainly by CYP3A4) and excreted in the urine. It has a short-elimination half-life of $2 \mathrm{~h}$ [18]. In contrast to other pharmacological sedatives, ketamine results in an increased heart rate, cardiac output and arterial blood pressure due to stimulation of the sympathetic nervous system and inhibition of noradrenaline reuptake. When used alone it has minimal effect on ventilatory drive, generally preserving airway patency and respiratory function, but may cause apnoea when used in combination with other pharmacological sedatives and opioids. An advantage of ketamine is that it is a potent bronchodilator and analgesic, but it has the disadvantage of causing increased salivation and secretions, not attenuating upper airway reflexes and resulting in emergence delirium (e.g. confusion and hallucinations) in $10-20 \%$ of adults [70]. The latter may be reduced with the co-administration of midazolam or propofol $[71,72]$. However, the co-administration of benzodiazepines with ketamine may result in a prolonged effect and attenuation of the cardiostimulatory effects of ketamine. Sympathetic antagonists such as $\beta$-blockers may unmask the myocardial depressant effects of ketamine. For moderate sedation, ketamine can be given intravenously as a bolus dose of $0.5 \mathrm{mg} \cdot \mathrm{kg}^{-1}$ and repeated every $5 \mathrm{~min}$ if required [36].

In the study of HWANG et al. [47], comparing the combination of propofol and alfentanil or propofol and ketamine via a patient controlled analgesia, ketamine was felt to be superior to alfentanil when combined with propofol. The sympathetic effects of ketamine maintained blood pressure values similar to pre-procedure levels and a higher percentage of patients in the propofol-ketamine group reported increased satisfaction with the procedure and demonstrated amnesia for the period of the bronchoscopy. The most commonly reported adverse effects by patients were delirium and hallucinations. As previously suggested [73], less propofol injection pain was seen in the propofol-ketamine group. A disadvantage to the use of ketamine is the longer duration of action compared to the other available sedatives currently used and the adverse effect of emergence delirium. 
TABLE 4 Summary of clinical studies of propofol in flexible bronchoscopy

\begin{tabular}{|c|c|c|c|}
\hline CLARKSon [54] & $\begin{array}{l}\text { Randomised, double-blind, } \\
\text { prospective-controlled } \\
\text { study }\end{array}$ & $\begin{array}{l}\text { Propofol }(n=21) \text { versus mid- } \\
\text { azolam }(n=20)\end{array}$ & $\begin{array}{l}\text { More rapid onset and recovery from sedation seen in the propofol group } \\
\text { No significant difference in the amount of topical anaesthetic required } \\
\text { or in oxygen desaturation }\end{array}$ \\
\hline Crawford [55] & $\begin{array}{l}\text { Randomised, double-blind, } \\
\text { prospective-controlled } \\
\text { study }\end{array}$ & $\begin{array}{l}\text { Propofol }(n=21) \text { versus mid- } \\
\text { azolam-alfentanil }(n=21)\end{array}$ & $\begin{array}{l}\text { In three patients in the midazolam-alfentanil and five in the propofol } \\
\text { group the depth of sedation exceeded the moderate level } \\
\text { Recovery to an appropriate level was more rapid in the latter group } \\
\text { Oxygen saturations decreased in both groups and there were no } \\
\text { significant differences in blood pressure } \\
\text { Those in the midazolam group had more amnesia and longer recovery time }\end{array}$ \\
\hline GonZALEZ [5] & $\begin{array}{l}\text { Randomised, single-blind, } \\
\text { prospective-controlled } \\
\text { study }\end{array}$ & $\begin{array}{l}\text { Propofol }(n=9) \text { versus no } \\
\text { sedation }(n=9)\end{array}$ & $\begin{array}{l}\text { Less cough, pain, sensation of asphyxiation, total amnesia and } \\
\text { improved tolerance of the procedure in the propofol group } \\
\text { No differences in oxygen saturations between the groups }\end{array}$ \\
\hline CLARK [20] & $\begin{array}{l}\text { Randomised, double-blind, } \\
\text { prospective-controlled } \\
\text { study }\end{array}$ & $\begin{array}{l}\text { Propofol }(n=43) \text { versus mid- } \\
\text { azolam }(n=39)\end{array}$ & $\begin{array}{l}\text { Propofol resulted in faster recovery from sedation and patient tolerance } \\
\text { and satisfaction were improved } \\
\text { There were no differences in operator satisfaction } \\
\text { Safely administered by non-anaesthetis }\end{array}$ \\
\hline Stoltz [56] & $\begin{array}{l}\text { Randomised, non-blinded, } \\
\text { prospective-controlled } \\
\text { study }\end{array}$ & $\begin{array}{l}\text { Propofol }(n=100) \text { versus } \\
\text { midazolam-hydrocodone } \\
(n=100)\end{array}$ & $\begin{array}{l}\text { Mean oxygen saturation and desaturation below } 90 \% \text { were similar in } \\
\text { both groups } \\
\text { Patients receiving propofol had less tachycardia during the procedure } \\
\text { and faster recovery from sedation }\end{array}$ \\
\hline GRENDELMEIER [12] & Prospective case series & Propofol $(n=440)$ & $\begin{array}{l}\text { Systolic blood pressure dropped below } 90 \mathrm{mmHg} \text { in } 15.4 \% \text { and oxygen } \\
\text { saturation dropped below } 90 \% \text { in } 16.4 \% \text { of patients but some of these } \\
\text { had higher American Society of Anesthesiology scores and were } \\
\text { already hypotensive or hypoxaemic prior to the sedation } \\
\text { None of the patients required intubation }\end{array}$ \\
\hline Yoon [57] & $\begin{array}{l}\text { Randomised, double-blind, } \\
\text { prospective-controlled } \\
\text { study }\end{array}$ & $\begin{array}{l}\text { Propofol }(n=32) \text { versus pro- } \\
\text { pofol-alfentanil }(n=32)\end{array}$ & $\begin{array}{l}\text { They did not find differences in patient or bronchoscopist satisfaction or in } \\
\text { degree of coughing but those in the alfentanil group had significantly lower } \\
\text { oxygen saturation levels. However, the lower levels of oxygen saturation } \\
\text { reported in the alfentanil are most likely not clinically significant }\end{array}$ \\
\hline SCHLATTER [58] & $\begin{array}{l}\text { Randomised, double-blind, } \\
\text { prospective-controlled } \\
\text { study }\end{array}$ & $\begin{array}{l}\text { Propofol }(n=154) \text { versus } \\
\text { propofol-hydrocodone } \\
(n=146)\end{array}$ & $\begin{array}{l}\text { This combination suppressed coughing and reduced patient discomfort } \\
\text { during flexible bronchoscopy compared to placebo alone with no } \\
\text { differences in complication rates }\end{array}$ \\
\hline CARMI [59] & $\begin{array}{l}\text { Randomised, non-blinded, } \\
\text { prospective-controlled } \\
\text { study }\end{array}$ & $\begin{array}{l}\text { Propofol }(n=56) \text { versus mid- } \\
\text { azolam-alfentanil }(n=59)\end{array}$ & $\begin{array}{l}\text { Those in the midazolam-alfentanil group rather than the propofol } \\
\text { group had higher carbon dioxide tension values and required more } \\
\text { oxygen supplementation or airway support; however, both were } \\
\text { considered equally safe and effective }\end{array}$ \\
\hline
\end{tabular}

\section{EMERGING PHARMACOLOGICAL SEDATIVES IN BRONCHOSCOPY \\ Fospropofol}

Fospropofol, 2,6-diisopropylphenol methoxyphosphonic acid, is a water-soluble pro-drug of propofol and has a longer onset and duration of action compared to the propofol lipid emulsion but has a much shorter elimination half-life [74]. Blood levels of propofol after administration of fospropofol reach lower peak levels and are more sustained than after administration of intravenous propofol leading to predictable 
levels of moderate sedation [74]. The advantage of its use is that it does not cause pain on injection, does not have the high risk of bacterial contamination seen with propofol and leads to predictable levels of sedation, however, it has the disadvantage that if a patient is over sedated they will require ventilatory support for longer and is associated with the commonly reported adverse effects paraesthesiae and pruritus [75, 76].

COHEN and co-workers [76, 77] conducted two randomised controlled trials of fospropofol or midazolam following premedication with fentanyl for colonoscopy and found that a dose of $6.5 \mathrm{mg} \cdot \mathrm{kg}^{-1}$ provided appropriate sedation and high patient satisfaction. SILVESTRI et al. [6] conducted a phase III randomised controlled trial of fospropofol $2 \mathrm{mg} \cdot \mathrm{kg}^{-1}$ and $6.5 \mathrm{mg} \cdot \mathrm{kg}^{-1}$ (those $>65$ years of age or with ASA category 3 or 4 had the dose reduced by $25 \%$ ). With the higher dose they found better sedation, absence of procedure recall and patient satisfaction. Hypoxia was seen in $15.4 \%$ of patients receiving the higher dose. In a subgroup analysis hypoxia was found to be more common in patients $>65$ years of age compared to younger patients $(13.1 \%$ versus $9.0 \%$, respectively) [78].

\section{Remifentanil}

Remifentanil is $\mu$-opioid receptor agonist with an analgesic potency similar to that of fentanyl that undergoes rapid metabolism by non-specific esterases in blood and has a short half-life of $<10 \mathrm{~min}$ [79]. The benefits of this being that its effects do not last long after discontinuing its administration irrespective of the duration of the infusion and there is no accumulation of the drug and metabolic toxicity in patients with hepatic dysfunction. In children sedated with propofol and remifentanil full awakening was seen $5 \pm 1.3$ min after stopping the remifentanil infusion [80].

Remifentanil has been used safely for flexible bronchoscopy in infants in combination with propofol [80, 81], but further studies are required to establish its role for flexible bronchoscopy compared with the other opiates. It is administered as an infusion at an initial rate of $0.1 \mu \mathrm{g} \cdot \mathrm{kg}^{-1} \cdot \mathrm{min}^{-1}$ and subsequently titrated in increments of $0.025 \mu \mathrm{g} \cdot \mathrm{kg}^{-1} \cdot \mathrm{min}^{-1}$ until the desired level of sedation is achieved but ideally shouldn't be $>0.2 \mu \mathrm{g} \cdot \mathrm{kg}^{-1} \cdot \mathrm{min}^{-1}$ due to the increased risk of apnoea and chest wall rigidity [82].

\section{Dexmedetomidine}

Dexmedetomidine is a selective $\alpha_{2}$-agonist with sedative and analgesic properties. It has the advantage of only causing mild respiratory depression at higher doses but does have sympathomimetic and vagolytic actions that may lead to bradycardia and hypotension [83]. These features are useful to attenuate the sympathetic response to intubation which it has been shown to do safely and effectively in flexible bronchoscopy for awake intubation [84] and in upper and lower gastrointestinal endoscopy [85-87], but it does require continuous cardiovascular monitoring to avoid unwanted complications. For upper gastrointestinal endoscopy dexmedetomidine resulted in a shorter recovery time and increased patient satisfaction when compared to midazolam [86]. Dexmedetomidine has been used successfully for bronchial thermoplasty [88] and recently for flexible bronchoscopy in a randomised controlled trial by RYU et al. [89]. Dexmedetomidine was co-administered with propofol and compared with propofol-remifentanil combination. The advantage of the dexmedetomidine was that it resulted in a lower incidence of oxygen desaturation and reduced need for oral cavity suction (reduced salivation and airway secretions), but it did result in prolonged recovery times, increased cough and lower bronchoscopist satisfaction scores when compared to remifentanil. Dexmedetomidine does not have anti-tussive properties like the opioids so increased cough is expected and but further trials are required to determine the role of this drug in bronchoscopy.

\section{Remimazolam}

Remimazolam is a novel short-acting GABA receptor agonist that is rapidly metabolised by non-specific tissue esterases and its action can be reversed with flumazenil [90]. Studies in sheep have shown that remimazolam has a more rapid onset of action and a shorter duration of action compared with midazolam but was associated with more pronounced respiratory depression and hypotension, similar to propofol [91]. In this study the respiratory depression correlated well with the depth of sedation. In a phase I trial in humans, it has been also been shown to have a faster onset of action and shorter duration of action than midazolam, without the resulting in the requirement for oxygen supplementation or ventilation with doses of $0.075-0.20 \mathrm{mg} \cdot \mathrm{kg}^{-1}$.

\section{DRUG INTERACTIONS}

Benzodiazepines, fentanyl, alfentanil and ketamine are metabolised by the CYP450 system (mainly CYP3A4). The action of CYP450 is altered by numerous drugs, which the bronchoscopist should be made aware of. Commonly used drugs such as the anti-retrovirals fluconazole, ketoconazole, erythromycin, diltiazem and cimitedine inhibit the CYP3A4 enzymes and prolong the effects of pharmacological sedatives [45]. This is of particular importance in patients on current antiretroviral treatment as these regimens contain either potent CYP3A4 inhibitors, such as the HIV protease inhibitor ritonavir, or enzyme inducers, such as the non-nucleoside reverse transcriptase inhibitors efavirenz or nevirapine [92]. Complications of the use of these drugs with antiretroviral treatment include prolonged sedation and arrhythmias and, in the study by Hsu et al. [93], co-administration of protease inhibitors with intravenous midazolam was associated with severe prolonged sedation, as well as increased length of hospital stay.

\section{CONCLUSION}

There is a definite need for anaesthetist delivered deep sedation (or general anaesthesia) for more prolonged and complex interventional pulmonology procedures. However, there should be further consideration of formal sedation training and credentialing for non-anaesthetists, supported by the currently available evidence that proceduralist-administered sedation is considered to be safe and cost-effective. Also, bronchoscopists need to be aware of the license available in their individual country for the use of the various pharmacological sedatives and practice within their competency. Higher-quality studies are needed to assess the efficacy of the emerging pharmacological sedatives as well as their cost-effectiveness in bronchoscopy, as the beneficial effects of individual sedatives on the process of clinical care, patient satisfaction and health resource utilisation may outweigh its acquisition cost. 
Given the evidence, propofol is an important agent for moderate sedation with benefits for patients and should be an alternative to current sedation regimens in proceduralistadministered sedation provided the user is appropriately trained and local guidelines allow this use. In the meantime, midazolam in combination with a short-acting opioid (fentanyl or alfentanil) remain the pharmacological agents of choice for proceduralist-administered sedation in bronchoscopy. Timely discharge is a priority.

\section{STATEMENT OF INTEREST}

None declared.

\section{REFERENCES}

1 Hatton MQ, Allen MB, Vathenen AS, et al. Does sedation help in fibreoptic bronchoscopy? BMJ 1994; 309: 1206-1207.

2 Morris LG, Zeitler DM, Amin MR. Unsedated flexible fiberoptic bronchoscopy in the resident clinic: technique and patient satisfaction. Laryngoscope 2007; 117: 1159-1162.

3 Smyth CM, Stead RJ. Survey of flexible fibreoptic bronchoscopy in the United Kingdom. Eur Respir J 2002; 19: 458-463.

4 Putinati S, Ballerin L, Corbetta L, et al. Patient satisfaction with conscious sedation for bronchoscopy. Chest 1999; 115: 1437-1440.

5 Gonzalez R, De-La-Rosa-Ramirez I, Maldonado-Hernandez A, et al . Should patients undergoing a bronchoscopy be sedated? Acta Anaesthesiologica Scand 2003; 47: 411-415.

6 Silvestri GA, Vincent BD, Wahidi MM, et al. A Phase 3, randomized, double-blind study to assess the efficacy and safety of fospropofol disodium injection for moderate sedation in patients undergoing flexible bronchoscopy. Chest 2009; 135: 41-47.

7 Rolo R, Mota PC, Coelho F, et al. Sedation with midazolam in flexible bronchoscopy - a prospective study. Revi Port Pneumol 2012; 18: 226-232.

$8 \mathrm{Ni}$ YL, Lo YL, Lin TY, et al. Conscious sedation reduces patient discomfort and improves satisfaction in flexible bronchoscopy. Chang Gung Med J, 33: 443-452.

9 Pickles J, Jeffrey M, Datta A, et al. Is preparation for bronchoscopy optimal? Eur Respir J 2003; 22: 203-206.

10 Wahidi MM, Jain P, Jantz M, et al. American College of Chest Physicians consensus statement on the use of topical anesthesia, analgesia, and sedation during flexible bronchoscopy in adult patients. Chest 2011; 140: 1342-1350.

11 Dang D, Robinson PC, Winnicki S, et al. The safety of flexible fibreoptic bronchoscopy and proceduralist-administered sedation: a tertiary referral centre experience. Int Med J 2012; 42: 300-305.

12 Grendelmeier P, Kurer G, Pflimlin E, et al. Feasibility and safety of propofol sedation in flexible bronchoscopy. Swiss Med Wkly 2011; 141: w13248.

13 Hassan C, Rex DK, Cooper GS, et al. Endoscopist-directed propofol administration versus anesthesiologist assistance for colorectal cancer screening: a cost-effectiveness analysis. Endoscopy 2012; 44: 456-464.

14 American Society of Anesthesiologists. Continuum of depth of sedation: definition of general anesthesia and levels of sedation/ analgesia. Park Ridge, ASA, 2009.

15 Rivera R, Antognini JF. Perioperative drug therapy in elderly patients. Anesthesiology 2009; 110: 1176-1181.

16 Chhajed PN, Wallner J, Stolz D, et al. Sedative drug requirements during flexible bronchoscopy. Respiration 2005; 72: 617-621.

17 Chhajed PN, Aboyoun C, Chhajed TP, et al. Sedative drug requirements during bronchoscopy are higher in cystic fibrosis after lung transplantation. Transplantation 2005; 80: 1081-1085.

18 Morgan GE, Mikhail MS, Murray MJ, eds. Clinical Anesthesiology. 3rd Edn. New York, McGraw-Hill 2001.
19 Ramsay MA, Savege TM, Simpson BRJ, et al. Controlled sedation with alphaxalone-alphadolone. Br Med J 1974; 2: 656-689.

20 Clark G, Licker M, Younossian AB, et al. Titrated sedation with propofol or midazolam for flexible bronchoscopy: a randomised trial. Eur Respir J 2009; 34: 1277-1283.

21 Lo YL, Lin TY, Fang YF, et al. Feasibility of bispectral index-guided propofol infusion for flexible bronchoscopy sedation: a randomized controlled trial. PloS One 2011; 6: e 27769.

22 World Health Organization. Surgical Safety Checklist. First Edition. www.who.int/patientsafety/safesurgery/tools_resources / SSSL_Checklist_finalJun08.pdf Date last accessed: March, 21, 2013.

23 Cowl CT, Prakash UB, Kruger BR. The role of anticholinergics in bronchoscopy. A randomized clinical trial. Chest 2000; 118: 188-192.

24 Malik JA, Gupta D, Agarwal AN, et al. Anticholinergic premedication for flexible bronchoscopy: a randomized, double-blind, placebo-controlled study of atropine and glycopyrrolate. Chest 2009; 136: 347-354.

25 Lundgren R, Häggmark S, Reiz S. Hemodynamic effects of flexible fiberoptic bronchoscopy performed under topical anesthesia. Chest 1982; 82: 295-299.

26 Matot I, Kramer MR. Sedation in outpatient fiberoptic bronchoscopy: alfentanil-propofol vs meperidine-midazolam. Anesthesiology 1997; 87: A12.

27 de Padua AI, de Castro M, Schmidt A, et al. Clonidine as a preanesthetic agent for flexible bronchoscopy. Respir Med 2004; 98: 746-751.

28 Rupp H, Maisch B, Brilla CG. Drug withdrawal and rebound hypertension: differential action of the central antihypertensive drugs moxonidine and clonidine. Cardiovasc Drugs Ther 1996; 10: Suppl. 1, 251-262.

29 Fox BD, Krylov Y, Leon P, et al. Benzodiazepine and opioid sedation attenuate the sympathetic response to fiberoptic bronchoscopy. Prophylactic labetalol gave no additional benefit. Results of a randomized double-blind placebo-controlled study. Respir Med 2008; 102: 978-983.

30 Schwarz Y, Greif J, Lurie O, et al. Dextromethorphan premedication reduces midazolam requirement: objective and subjective parameters in peribronchoscopy. Respiration 2007; 74: 314-319.

31 Vesco D, Kleisbauer JP, Orehek J. Attenuation of bronchofiberscopy-induced cough by an inhaled $\beta 2$-adrenergic agonist, fenoterol. Am Rev Respir Dis 1988; 138: 805-806.

32 Tsunezuka $\mathrm{Y}$, Sato $\mathrm{H}$, Tsukioka $\mathrm{T}$, et al. The role of codeine phosphate premedication in fibre-optic bronchoscopy under insufficient local anaesthesia and midazolam sedation. Respir Med 1999; 93: 413-415.

33 US Food and Drug Administration. FDA Drug Safety Communication: Codeine use in certain children after tonsillectomy and/or adenoidectomy may lead to rare, but life-threatening adverse events or death. www.fda.gov/Drugs/DrugSafety/ ucm313631.htm Date last updated: August 16, 2012. Date last accessed: July 29, 2012.

34 Maltais F, Laberge F, Laviolette M. A randomized, double-blind, placebo-controlled study of lorazepam as premedication for bronchoscopy. Chest 1996; 109: 1195-1198.

35 Watts MR, Geraghty R, Moore A, et al. Premedication for bronchoscopy in older patients: a double-blind comparison of two regimens. Respir Med 2005; 99: 220-226.

36 Fassoulaki A, Theodoraki K, Melemeni A. Pharmacology of sedation agents and reversal agents. Digestion 2010; 82: 80-83.

37 Williamson $\mathrm{BH}$, Nolan PJ, Tribe AE, et al. A placebo controlled study of flumazenil in bronchoscopic procedures. $\mathrm{Br} \mathrm{J} \mathrm{Clin}$ Pharmacol 1997; 43: 77-83.

38 Dundee JW, Collier PS, Carlisle RJT, et al. Prolonged midazolam elimination half-life. Br J Clin Pharmacol 1986; 21: 425-429.

39 eMC. Summary of Product Characteristics. Flumazenil $0.1 \mathrm{mg} \cdot \mathrm{mL}^{-1}$ solution for injection. www.medicines.org.uk/EMC/medicine/ 
26619/SPC/Flumazenil+0.1+mg+mL+solution+for+injection Date last updated: June 28, 2012. Date last accessed: July 28, 2012.

40 Cases Viedma E, Pérez Pallarés J, Martínez García MA, et al. [A randomised study of midazolam for sedation in flexible bronchoscopy]. Arch Bronconeumol 2010; 46: 302-309.

41 eMC. Summary of Product Characteristics. Naloxone 400 micrograms $/ \mathrm{mL}$ solution for Injection (hameln). www.medicines.org. uk/EMC/medicine/21095/SPC/Naloxone+400+micrograms+mL+ solution+for+Injection+(hameln) Date last updated: August 15, 2008. Date last accessed: July 30, 2012.

42 Ngai SH, Berkowitz BA, Yang JC, et al. Pharmacokinetics of naloxone in rats and in man: basis for its potency and short duration of action. Anesthesiology 1976; 44: 398-401.

43 eMC. Summary of Product Characteristics. Fentanyl 50 micrograms/mL Injection BP. www.medicines.org.uk/EMC/medicine/ 27155/SPC/Fentanyl+50+microgram+ml+Injection/ Date last accessed: March 25, 2013.

44 Papagiannis A, Smith AP. Fentanyl versus midazolam as premedication for fibre optic bronchoscopy. Respir Med 1994; 88: 797-788.

45 eMC. Summary of Product Characteristics. Alfentanil 500 micrograms $/ \mathrm{mL}$ solution for injection. www.medicines.org.uk/EMC/ medicine/21358/SPC/Alfentanil+500+micrograms+mL+solution+ for+injection Date last updated: July 27, 2011. Date last accessed: July 30, 2012.

46 Houghton CM, Raghuram A, Sullivan PJ, et al. Pre-medication for bronchoscopy: a randomised double blind trial comparing alfentanil with midazolam. Respir Med 2004; 98: 1102-1107.

47 Hwang J, Jeon Y, Park HP, et al. Comparison of alfetanil and ketamine in combination with propofol for patient-controlled sedation during fiberoptic bronchoscopy. Acta Anaesthesiol Scand 2005; 49: 1334-1338.

48 Dreher M, Ekkernkamp E, Storre JH, et al. Sedation during flexible bronchoscopy in patients with pre-existing respiratory failure: midazolam versus midazolam plus alfentanil. Respiration 2010; 79 : 307-314.

49 Greig JH, Cooper SM, Kasimbazi HJ, et al. Sedation for fibre optic bronchoscopy. Respir Med 1995; 89: 53-56.

50 Usta B, Türkay C, Muslu B, et al. Patient-controlled analgesia and sedation with alfentanyl versus fentanyl for colonoscopy: a randomized double blind study. J Clin Gastroenterol 2011; 45: e72-e75.

51 eMC. Summary of Product Characteristics. Diprivan 1\%. www. medicines.org.uk/EMC/medicine/2275/SPC/Diprivan+1 Date last updated: January 26, 2012. Date last accessed: August 1, 2012.

52 Jalota L, Kalira V, George E, et al. Prevention of pain on injection of propofol: systematic review and meta-analysis. BMJ 2011; 342: d1110.

53 Hepner DL, Castells MC. Anaphylaxis during the perioperative period. Anesth Analg 2003; 97: 1381-1395.

54 Clarkson K, Power CK, Oconnell F, et al. A comparative evaluation of propofol and midazolam as sedative agents in fiberoptic bronchoscopy. Chest 1993; 104: 1029-1031.

55 Crawford M, Pollock J, Anderson K, et al. Comparison of midazolam with propofol for sedation in outpatient bronchoscopy. Br J Anaesth 1993; 70: 419-422.

56 Stolz D, Kurer G, Meyer A, et al. Propofol versus combined sedation in flexible bronchoscopy: a randomised non-inferiority trial. Eur Respir J 2009; 34: 1024-1030.

57 Yoon HI, Kim JH, Lee JH, et al. Comparison of propofol and the combination of propofol and alfentanil during bronchoscopy: a randomized study. Acta Anaesthesiol Scand 2011; 55: 104-109.

58 Schlatter L, Pflimlin E, Fehrke B, et al. Propofol versus propofol plus hydrocodone for flexible bronchoscopy: a randomised study. Eur Respiry J 2011; 38: 529-537.

59 Carmi U, Kramer MR, Zemtzov D, et al. Propofol safety in bronchoscopy: prospective randomized trial using transcutaneous carbon dioxide tension monitoring. Respiration 2011; 82: 515-521.
60 Short TG, Plummer JL, Chui PT. Hypnotic and anaesthetic interactions between midazolam, propofol and alfentanil. $\mathrm{Br} \mathrm{J}$ Anaesth 1992; 69: 162-167.

61 Mertens MJ, Olofsen E, Engbers FH, et al. Propofol reduces perioperative remifentanil requirements in a synergistic manner: response surface modeling of perioperative remifentanil-propofol interactions. Anesthesiology 2003; 99: 347-359.

62 Jensen JT, Banning AM, Clementsen P, et al. Nurse administered propofol sedation for pulmonary endoscopies requires a specific protocol. Dan Med J 2012; 59: A4467.

63 Cohen LB, Hightower CD, Wood DA, et al. Moderate level sedation during endoscopy: a prospective study using low-dose propofol, meperidine/fentanyl, and midazolam. Gastrointest Endosc 2004; 59: 795-803.

64 Sipe BW, Scheidler M, Baluyut A, et al. A prospective safety study of a low-dose propofol sedation protocol for colonoscopy. Clin Gastroenterol Hepatol 2007; 5: 563-566.

65 Practice guidelines for sedation and analgesia by non-anesthesiologists. Anesthesiology 2002; 96: 1004-1017.

66 Bosslet GT, Devito ML, Lahm T, et al. Nurse-administered propofol sedation: feasibility and safety in bronchoscopy. Respiration 2010; 79: 315-321.

67 Rex DK, Deenadayalu VP, Eid E, et al. Endoscopist-directed administration of propofol: a worldwide safety experience. Gastroenterology 2009; 137: 1229-1237.

68 Berkenbosch JW, Graff GR, Stark JM. Safety and efficacy of ketamine sedation for infant flexible fiberoptic bronchoscopy. Chest 2004; 125: 1132-1137.

69 Law AK, Ng DK, Chan KK. Use of intramuscular ketamine for endoscopy sedation in children. Pediatr Int 2003; 45: 180-185.

70 Strayer RJ, Nelson LS. Adverse events associated with ketamine for procedural sedation in adults. Am J Emerg Med 2008; 26: 985-1028.

71 Sener S, Eken C, Schultz CH, et al. Ketamine with and without midazolam for emergency department sedation in adults: a randomized controlled trial. Ann Emerg Med 2011; 57: 109-114.e2.

72 Andolfatto G, Willman E. A prospective case series of singlesyringe ketamine-propofol (Ketofol) for emergency department procedural sedation and analgesia in adults. Acad Emerg Med 2011; 18: 237-245.

73 Tan $\mathrm{CH}$, Onsiong MK, Kua SW. The effect of ketamine pretreatment on propofol injection pain in 100 women. Anaesthesia 1998; 53: 302-305.

74 Boules R, Szkiladz A, Nogid A. Fospropofol disodium (lusedra) injection for anesthesia-care sedation: a clinical review. P.T. 2012; 37: 395-422.

75 Lusedra (fospropofol disodium) Injection, prescribing information. Woodcliff Lake, USA, Eisai Inc., 2009. http://us.eisai.com/ package_inserts/Lusedra\%20PI.pdf Date last accessed: August 1, 2012.

76 Cohen LB, Cattau E, Goetsch A, et al. A randomized, double-blind, phase 3 study of fospropofol disodium for sedation during colonoscopy. J Clin Gastroenterol, 44: 345-353.

77 Cohen LB. Clinical trial: a dose-response study of fospropofol disodium for moderate sedation during colonoscopy. Aliment Pharmacol Ther 2008; 27: 597-608.

78 Silvestri G, Vincent B, Wahidi MM. Fospropofol disodium for sedation in elderly patients undergoing flexible bronchoscopy. J Bronchol Interv Pulmonol 2011; 18: 15-22.

79 Bürkle H, Dunbar S, Van Aken H. Remifentanil: a novel, shortacting, $\mu$-opioid. Anesth Analg 1996; 83: 646-651.

80 Reyle-Hahn M, Niggemann B, Max M, et al. Remifentanil and propofol for sedation in children and young adolescents undergoing diagnostic flexible bronchoscopy. Paediatr Anaesth 2000; 10: 59-63.

81 Berkenbosch JW, Graff GR, Stark JM, et al. Use of a remifentanilpropofol mixture for pediatric flexible fiberoptic bronchoscopy sedation. Paediatr Anaesth 2004; 14: 941-946. 
82 eMC. Summary of Product Characteristics. Ultiva Injection. www. medicines.org.uk/EMC/medicine/14766/SPC/Ultiva+Injection Date last updated: January 4, 2011. Date last accessed: August 1, 2012.

83 Kamibayashi T, Maze M. Clinical uses of $\alpha 2$-adrenergic agonists. Anesthesiology 2000; 93: 1345-1349.

84 Bergese SD, Candiotti KA, Bokesch PM, et al. A phase IIIb, randomized, double-blind, placebo-controlled, multicenter study evaluating the safety and efficacy of dexmedetomidine for sedation during awake fiberoptic intubation. Am J Ther, 17: 586-595.

85 Demiraran Y, Korkut E, Tamer A, et al. The comparison of dexmedetomidine and midazolam used for sedation of patients during upper endoscopy: a prospective, randomized study. Can J Gastroenterol 2007; 21: 25-29.

86 Vázquez-Reta JA, Jiménez Ferrer MC, Colunga-Sánchez A, et al. [Midazolam versus dexmedetomidine for sedation for upper gastrointestinal endoscopy.]. Rev Gastroenterol Mex, 76: 13-18.

87 Dere K, Sucullu I, Budak ET, et al. A comparison of dexmedetomidine versus midazolam for sedation, pain and hemodynamic control, during colonoscopy under conscious sedation. Eur J Anaesthesiol 2010; 27: 648-652.

88 Lee JA, Rowen DW, Rose DD. Bronchial thermoplasty: a novel treatment for severe asthma requiring monitored anesthesia care. AANA J 2011; 79: 480-483.

89 Ryu JH, Lee SW, Lee JH, et al. Randomized double-blind study of remifentanil and dexmedetomidine for flexible bronchoscopy. $\mathrm{Br} \mathrm{J}$ Anaesth 2012; 108: 503-511.

90 Kilpatrick GJ, McIntyre MS, Cox RF, et al. CNS 7056: a novel ultrashort-acting Benzodiazepine. Anesthesiology 2007; 107: 60-66.

91 Upton RN, Martinez AM, Grant C. Comparison of the sedative properties of CNS 7056, midazolam, and propofol in sheep. $\mathrm{Br} \mathrm{J}$ Anaesth 2009; 103: 848-857.

92 José RJ, Marshall N, Lipman MC. Important antiretroviral drug interactions with benzodiazepines used for sedation during bronchoscopy. Chest 2012; 141: 1125.

93 Hsu AJ, Carson KA, Yung R, et al. Severe prolonged sedation associated with coadministration of protease inhibitors and intravenous midazolam during bronchoscopy. Pharmacotherapy 2012; 32: 538-545. 